\title{
Analisis Forecasting Komoditi Strategis Daerah Serta Ketahanan Pangan Yang Berkelanjutan
}

\author{
Ade Firmansyah Tanjung1 \\ Salsabila ${ }^{2 *}$ \\ Aflahun Fadhly Siregar ${ }^{3}$ \\ 1,2,3Universitas Muhammadiyah Sumatera Utara, Medan, Indonesia \\ *email: salsabila@umsu.ac.id \\ Diterima: Juli 2020; Disetujui: Maret 2021; Dipublish: April 2021
}

\begin{abstract}
Abstrak
Pertanian memberikan peran untuk ekonomi masyarakat desa dan pangan nasional. Usahatani padi merupakan penghasil pangan paling utama dikalangan masyarakat. Untuk Metode digunakan forecasting produksi dengan data produksi tahun 2010 - 2019 di Provinsi Sumatera Utara dan SWOT untuk menentukan strategi pemerintah daerah Kabupaten Langkat dengan jumlah responden berjumlah 5 orang ahli dalam bidang pangan. Hasil olah data penelitian, untuk forecasting, produksi padi mengalami trend positif per tahun sebesar 134.681 ton, untuk tahun 2020 sebesar 4.647.876 ton dan diprediksi ditahun 2030 sebesar 5.994 .690 ton. Untuk SWOT, hasil olah data untuk skor selisih untuk strategi dititik kuadran II (Strategi Divesifikasi) berarti posisi ini memiliki kekuatan untuk meminimalkan ancaman dan tantangan untuk pemerintah daerah mewujudkan ketahanan pangan berkelanjutan.
\end{abstract}

Kata Kunci: Produksi, Focecasting, Eksternal, Internal, SWOT

\begin{abstract}
Agriculture provides a role for the economy of rural communities and national food. Rice farming is the main food producer among the community. For the method used for production forecasting with production data for 2010 - 2019 in North Sumatra Province and SWOT to determine the strategy of the Langkat Regency local government with 5 respondents in the food sector. The results of research data processing, for forecasting, rice production experienced a positive trend per year of 134,681 tons, for 2020 amounting to 4,647,876 tons and it is predicted that in 2030 it will be 5,994,690 tons. For SWOT, the result of data processing for the difference score for the strategy in quadrant II (Strategy Divesification) means that this position has the power to minimize threats and challenges for local governments to achieve sustainable food security.
\end{abstract}

Keywords: Production, Focecasting, External, Internal, SWOT

\section{PENDAHULUAN}

Pandangan untuk pertanian berkelanjutan sudah tersosialisasi untuk secara global sebagai bentuk arah ideal untuk pembangunan pertanian. (Rahmanta, 2014). Dalam kondisi global dilihat sepuluh tahun kedepan negaranegara berkembang termasuk Indonesia menghadapi keadaan yang semakin sulit dalam pencapaian, mempertahankan, dan untuk dapat meningkatkan kualitas dalam keberlanjutan ketahananpangan.
Sisi supply (penawaran, pasokan) dan sisi demand (permintaan, kebutuhan) yang berperilaku sangat dinamis yang menjadi pengaruh dari tantangan dalam ketahanan pangan (Suryana, 2014).

Dari hasil sensus Badan Pusat Statistik, Provinsi Sumatera Utara merupakan jumlah penduduk terbesar ke 4 (empat) di Indonesia. Untuk jumlah keseluruhanpenduduk ditahun 2014 jumlah penduduk 13.766.851 jiwa dan meningkat ditahun 2018 jumlah 
penduduk 14.415.391 jiwa. (Badan Pusat Statistik, 2019).

Dari data badan pusat statistik, terdapat beberapa daerah di Provinsi Sumatera Utara yang memiliki produktivitas terbesar di tahun 2018, yang termasuk dalam 5 (lima) daerah Kabupaten tersebut salah satunya adalah Kabupaten Langkat yang memiliki jumlah luasan panen 20.573 ha dan Produksi 114445 ton (Badan Pusat Statistik, 2019).

Periode 5 (lima) tahun terakhir rata-rata di Kabupaten Langkat ada 2 (dua) sektor basis, yaitu sektor pertanian, kehutanan, perikanan (PKP) dan sektor pengadaan listrik dan gas. Dari 2 (dua) sektor ini dapat juga memenuhi kebutuhan diluar daerahnya. Untuk sektor basis pertama, subsektor yang paling unggulan adalah perkebunan, kemudianuntuk yang kedua diikuti dengan tanaman pangan. Hasil analisis typology klassen yang dilakukan, klasifikasi sektor pertanian, kehutanan dan perikanan berada di kuadran II, tergolong stagnant sector, disebabkan oleh laju pertumbuhan lebih kecil bila dibandingkan dengan pertumbuhan pada tingkat Provinsi Sumatera Utara. Pertahunnya sektor ini bias jugaakan mengalami penurunan dan tidak menjadi sektor unggulan, disebabkan pertumbuhannya yang tertekan. Baik itu dilihat dari segi hasil produksi maupun luas panen padi sawah (Desi Novita, 2017).

Padikomoditi prioritas, yang merupakan penghasil kebutuhan utama tanpa terkecuali di Provinsi Sumatera Utara yang belum tergantikan. Perlu berbagai cara dalam peningkatan produksi padi sebagai wujud peningkatan ketahanan pangan. Pola tanam yang dikembangkanseperti yang diungkapkan (Ernawati, 2012), salahsatunya palawija diharapkan dapat meningkatkan taraf hidup masyarakat setempat yang mayoritas adalah petani.

Dari berbagai urgensi masalah ini, maka peneliti akan melakukan pemberian informasi tentang prediksi produksi padi di Provinsi Sumaera untuk10 tahun ke depan yang dapat berguna untuk pertimbangan penentu kebijakan. setelah itu, peneliti membuat strategi tepat untuk pemerintah daerah di Kabupaten Langkat, untuk ketahanan pangan berkelanjutan sebagai sentra produksi padi.

\section{METODE PENELITIAN}

Lokasi penelitian di Provinsi Sumatera Utara di Kabupaten Langkat. dengan alasan salah satu daerah yang memiliki produksi yang baik untuk komoditi pangan, salah satunya adalah padi. Untuk analisis data dalam penelitian terbagi 2 (dua) yaitu Peramalan dan SWOT.

Penelitian peramalan memakai data produksi padi di Provinsi Sumatera Utara. Untuk SWOT strategi pemerintah daerah melalui wawancara dan kuesioner ke 5 (Orang) ahli pangan di Kabupaten Langkat.

Pengambilan sampel dilakukan dengan metode expert sampling (sampling ahli) dan judgement sampling (pengambilan sampel keputusan).

Untuk penentuan sampel analisis SWOT dilakukandengan metode sampel nonprobabilitas secara expert sampling (sampling ahli), dengan pertimbangan metode probability kurang efektif untuk 
biaya dan waktu bagi peneliti. (Lubis, dkk. 2018).

Judgement sampling dilakukan dengan pengambilan sampel yang Tabel 1. Instrumen Penelitian

\begin{tabular}{lllll}
\hline No & Variabel & Sumber Data & Metode & Sumber Informasi \\
\hline 1. & Forecasting & Badan Pusat & - Pengambilan data & - Sumatera utara \\
& & Statistik & produksi padi sawah & dalam angka \\
& & Dinas Ketahanan & - Wawancara & $-2010-2019$ \\
2. & SWOT & $\begin{array}{l}\text { Pangan Kabupaten } \\
\text { Langkat }\end{array}$ & - Observasi. & $\begin{array}{l}\text { ketahanan } \\
\text { pangan }\end{array}$ \\
& & & Phidang \\
\hline
\end{tabular}

\section{Sumber: Data Sekunder}

Dalam penelusuran data ini dilakukan pengumpulan data bentuk primer dan bentuk sekunder.

Pengumpulan data dilakukan langsung oleh peneliti dari sumber awal disebut data primer, sedangkan untuk pengambilan data yang didapatkan peneliti tidak langsung dari subjek penelitian disebut data sekunder. (Suliyanto, 2018).

Penelitian iniakan melakukan wawancara dan observasi untuk proses pengumpulan data primer dan sekunder. Wawancara itu meruapakan proses mendapatkan keterangan/data untuk keperluan penelitian melalui tanya jawab dengan tatap muka. (Siregar, 2013). Observasi adalah pengamatan secara langsung melalui pencatatan perilaku seseorang atau peristiwa tanpa melalui proses pertanyaan. (Syaiful, 2018) .

Untuk identifikasi masalah pertama, Menurut Supranto (1989), untuk perhitungan peramalan dengan metode Least Square (kuadrat terkecil) dapat digunakan dengan persamaan berikut ini :

$\mathrm{Y}=\mathrm{a}+\mathrm{bx}+\mathrm{e}$. dipercaya mempunyai posisi sesuai untuk memberikan keperluan informasi. (Suvriana, 2016).

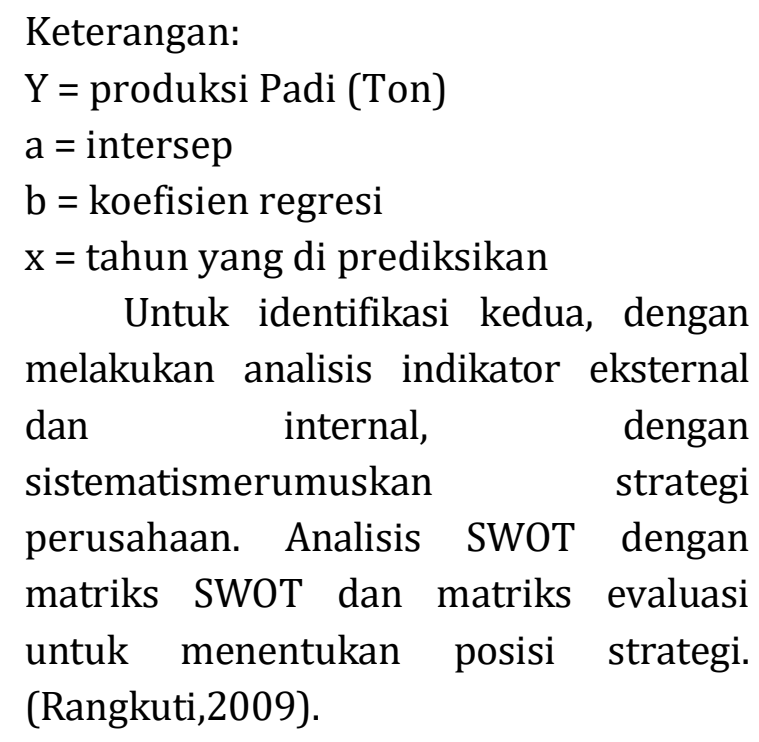

\section{HASIL DAN PEMBAHASAN}

Analisis Forecasting

Analisis forecasting produksi padi sawah di Provinsi Sumatera Utara dihasilkan dengan pengolahan data 10 tahun terakhir melalui Least Squares Method Regresi Linier Sederhana, dengan persamaan berikut ini:

$$
\mathrm{Qi}=3907128.3+67340.7 \mathrm{x}
$$

Dengan persamaan tersebut, memberikan informasi adanya trend produksi padi sawah dari tahun 2020 sampai 2030 , trend prediksi meningkat. untuk prediksi data produksidapat dilihat tabel berikut ini ; 
Tabel 2. Forecasting produksi padi sawah tahun 2020 - 2030

\begin{tabular}{ccc}
\hline Tahun & X & Produksi \\
\hline 2020 & 11 & 4.647 .876 \\
2021 & 13 & 4.782 .557 \\
2022 & 15 & 4.917 .239 \\
2023 & 17 & 5.051 .920 \\
2024 & 19 & 5.186 .602 \\
2025 & 21 & 5.321 .283 \\
2026 & 23 & 5.455 .964 \\
2027 & 25 & 5.590 .646 \\
2028 & 27 & 5.725 .327 \\
2029 & 29 & 5.860 .009 \\
2030 & 31 & 5.994 .690 \\
\hline
\end{tabular}

Sumber: Data Sekunder Diolah 2020

Peramalan produksi padi mengalami proses peningkatan per tahunnya berjumlah 134.681 ton, terlihat dari tahun 2020 berjumlah 4.647.876 ton dan diprediksi tahun 2030 berjumlah 5.994 .690 ton. Untuk trend produksi menghasilkan proses peningkatan positif dimasa mendatang.

Peningkatan produksi positif juga perlu karena adanya penggunaan input produksi yang optimal, seperti yang diungkapkan (Ifgayani et al., 2019), mengatakan bahwa luas lahan, pupuk Urea, tenaga kerja, benih dan pupuk phonska, hasil penelitian menunjukkan secara uji simultan regresi linier berganda dapat mempengaruhi produksi padi sawah. Hal ini juga sesuai dengan yang ungkapkan (Muhajirin et al., 2014), bahwa pupuk sp36, benih pestisida, tenaga kerja, pupuk kcl, luas lahan dan benih juga secara keseluruhan dapat berpengaruh terhadap produksi usahatani padi sawah.

\section{Ketahanan pangan Berkelanjutan}

Untuk mewujudkan ketahanan pangan berkelanjutan perlu diketahui beberapa hal yang menjadi pilar utama.
Sesuai dengan apa yang diungkapkan (Pusvita et al., 2019), hasil penelitian tersebut menunjukkan bahwa ketahanan pangan itu dipengaruhi oleh 3 (tiga) hal yaitu ketersediaan pangan, stabilitas pangan, dan akses pangan.

Penelusuran ke lokasi dihasilkan beberapa indikator internal dalam penyusunan strategi ketahanan pangan berkelanjutan:

\section{Koordinasi Kelembagaan}

Kesamaan untuk pandangan pemerintah daerah dalam memahami pentingnya membangun koordinasi antar kelembagaan pangan dalam mewujudkan ketahanan pangan berkelanjutan menjadi penting. Dengan melakukan integrasi antar kelembagaan dan sistem penyuluhan pertanian dengan program pemerintah daerah. Demi kelancaran tujuan yang ingin dicapai, melalui integrasi akan mempermudah jalannya pelaksanaan program. Berdasarkan yang diungkapkan oleh (Darus et al., 2020) lembaga penyuluhan berperan dalam melaksanakan pengembangan sumber daya manusia dan penguatan terhadap kelembagaan petani sebagai diseminasi informasi/inovasi, wadah edukasi, konsultasi dan supervise dan fasilitasi.

Komitmen Pemerintah Daerah

Pemerintah daerah terus mendorong peran sektor pertanian dalam mencapai ketahanan pangan. Komitmen harus tetap dijaga dengan berbagai kebijakan program terkait cadangan pangan, diversifikasi pangan, serta mengembangkan sektor pertanian modern. Peran dari pemerintah melalui kebijakan memang sangat diperlukan 
untuk menjaga kestabilan dan ketersediaan pangan agar ketahanan pangan berkelanjutan. Berdasarkan apa yang diungkapkan oleh (Amir, 2020), untuk mendorong ketahanan pangan pemerintah daeah bisa melakukan strategi seperti percepatan penganekaragaman pangan dan gizi, pengembangan dan membentuk lumbung pangan dan desa mandiri pangan

\section{Peran Sumber Daya Manusia}

Dengan adanya desentraliasi, maka daerah sebagai pelaksana untuk membangun ketahanan pangan, akan memerlukan SDM di bidang pertanian yang memadai. Menuju ketahanan pangan harus dijadikan prioritas utama bagi pemerintah daerah, untuk itu diperlukan SDM terbaik untuk mampu melaksanakan program. Sumber daya manusia yang tangguh dalam penyelesaian berbagai persoalan pangan memang sangat diperlukan untuk kelancaran tujuan yang ingin dicapai. Sejalan dengan yang diungkapkan oleh (Juarini, 2015), perlunya pembinaan unsur intuisi pada sumber daya manusia yang lebih fokus pada 4 (empat) unsur yakni afeksi, psikomotor, kognisi, dan intuisi.

\section{Sosialisasi Program Pemerintah}

Diperlukan perubahan sosialisasi untuk program pemerintah daerah dengan pendekatan-pendekatan yang sesuai dengan tujuan pelaksanaan program, supaya lebih mudah mendapatkan kesamaan memahami program dan target mencapai ketahanan pangan berkelanjutan dapat terwujud. Untuk sosialiasi ini dapat dilakukan pendekatan partisipatif pemerintah daerah melalui kelembagaan pertanian. Sejalan dengan yang diungkapkan oleh (Elizabeth, 2019), dengan adanya pelaksanaan terhadap peningkatan dan pemberdayaan bagi fungsi serta peran kelembagaan pertanian dan pedesaan adalah salah satu bagian dari aspek program pembangunan pertanian berkelanjutan dan berkesinambungan. Luas lahan

Tantangan untuk pemerintah daerah ketika menghadapi masalah alih fungsi lahan. Keterbatasan akan lahan usahatani akan menjadi tantangan untuk menjaga produktivitas padi dan secara keseluruhan berdampak untuk ketersediaan pangan. Pemerintah memiliki tantangan yang cukup berat ketika harus dihadapkan berbagai peristiwa alih fungsi lahan yang terjadi. Masalah ini akan berdampak pada stabilitas dan ketersediaan pangan. Sesuai dengan yang diungkapkan oleh (Hidayat, 2020), bahwa penurunan luas lahan akibat alih fungsi lahan akan berpengaruh signifikan pada produksi bagi pangan paling utama yakni jagung, padi, dan kedelai.

Penelusuran ke lokasi dihasilkan beberapa indikator internal dalam penyusunan strategi ketahanan pangan berkelanjutan:

\section{Infrastruktur Pangan}

Masalah akses distribusi menjadi hambatan pasokan pangan, ditambah lagi daerah yang rentan defisit pangan dan lokasinya sulit untuk terjangkau. Permasalahan ini akan menyebabkan gejolak harga pangan. Selain itu kegiatan usahatani juga kebanyakan musiman, 
diperlukan aturan perencanaan sistem saluran pemasaran, serta distribusi yang lebih efektif dan efisien. Saat ini infrastruktur distribusi pangan sudah baik. Berdasarkan yang diungkap oleh (Widodo, 2013) untuk perencanaan akses pangan dapat dilakukan dengan Percepatan Penganekaragaman Konsumsi Pangan (P2KP) dan Penanganan Daerah Rawan Pangan.

\section{Teknologi Pangan Lokal}

Perkembangan untuk percepatan teknologi pangan lokal diperlukan sebagai upaya untuk mewujudkan ketahanan pangan. Untuk terus mendukung percepatan inovasi, dengan berkolaborasi antara pemerintah daerah dengan berbagai lembaga riset, stakeholder dan perguruan tinggi serta partisipasi masyarakat lainnya. Berdasarkan yang telah diungkapkan oleh (Marsigit, 2010), desa mandiri pangan perlu diarahkan dalam pengembangan produk pangan lokal

\section{Kondisi Letak Daerah}

Perbedaan kondisi geografis, maka komoditi dan akses distribusi yang dihasilkan juga berbeda. Dengan perkembangan percepatan perubahan teknologi di masa revolusi industri 4.0, diharapkan menjadi solusi bagi permasalahan kondisi geografis. Untuk lokasi penelitian memiliki keuntungan geografis yang sangat produktif untuk menghasilkan komoditi pangan.

\section{Alih Fungsi}

Laju alih fungsi pertanian ke tanaman komersil atau non usahatani, agar dapat dihambat melalui kebijakan untuk mempertahankan kondisi lahan pertanian. Diharapkan dapat menahan lajunya peningkatan perubahan fungsi lahan pertanian. Berdasarkan penelitian yang telah dilakukan oleh Prasada., et .al (2018), menurunnya jumlah luas lahan disebabkan karena adanya alih fungsi lahan sawah, sehingga telah memberikan dampak langsung bagi penurunan jumlah pangan yang bisa diproduksi tapi dengan asumsi produktivitas tetap. hasil uji $t$ yang dilakukan, adanya perbedaan sebelum dan sesudah alih fungsi lahan sawah.

\section{Harga Pangan}

Fluktuasi harga juga dapat menimbulkan inflasi, untuk itu upaya pemerintah daerah adalah menjaga harga pangan tetap stabil dan terjangkau. Perbedaan letak geografis pada setiap daerah juga dapat berdampak pada harga pangan serta semakin menurunnya stok pangan yang tersedia. Sesuai yang diungkapkan oleh Jaya (2018), kebijakan untuk penetapan harga beras, idealnya mampu melakukan perlindungan bagi petani agar tidak akan mengalami kerugian, dan melindungi konsumen supaya dapat mendapatkan beras sesuai harga yang terjangkau.

\section{Lembaga Penelitian}

Adanya inovasi-inovasi terhadap teknologi pangan lokal sebagai bentuk upaya dukungan untuk meningkatkan produktifitas padi, untuk mewujudkan ini pemerintah daerah harus berkolaborasi dengan lembaga penelitian, pihak akademisi, maupun stakeholder lainnya. Untuk lebih mengetahuai berbagai persoalan pertanian dari hulu sampai hilir. Sesuai dengan yang ungkapkan oleh (Darus et 
al., 2020) untuk peran dari lembaga perguruan tinggi bahwa masih kurang dirasakan bagi petani secara langsung melalui pembinaan terhadap petani dalam meningkatkan hasil produktivitas usahatani. Hasil matriks internal dan eksternal dengan total skor pembobotan di daerah penelitian adalah Indikator internal, bernilai 1 merupakan selisih kekuatan dengan kelemahan, dengan nilai ini kekuatan lebih besar dibandingkan kelemahan.

Indikator eksternal, dengan nilai 0,50 merupakan selisih peluang dengan ancaman bahwa ancaman lebih besar dari peluang. Perhitungan skor tertimbang pada Tabel 3, untuk posisi strategi mewujudkan ketahanan pangan berkelanjutan berada kuadran II (Strategi Diversifikasi). Hal ini sesuai dengan berdasarkan yang diungkapkan oleh (Ariesa, 2019), untuk mewujudkan kemandirian pangan perlu adanya peranan pemerintah dan masyarakat. Ujung tombak penyediaan pangan yakni petani, harus memperoleh perhatian dan dukungan pemerintah daerah dan kebijakan harga dari pemerintah daerah juga bisa mendukung untuk memantapkan dan mewujudkan kemandirian pangan.

\section{SIMPULAN}

Forecasting produksi mengalami peningkatan pertahunnya berjumlah 134.681 ton, dari tahun 2020 sebesar 4.647.876 ton dan diprediksi ditahun 2030 berjumlah 5.994 .690 ton. Trend peningkatan yang positif. Posisi strategi kuadran II (Strategi Diversifikasi) memiliki kekuatan lebih besar untuk menghadapi ancaman dan tantangan bagi pemerintah daerah Kabupaten Langkat dalam mewujudkan ketahanan pangan berkelanjutan

\section{DAFTAR PUSTAKA}

Amir, H. A. (2020). Peran Pemerintah Daerah Dalam Mendukung Ketahanan Pangan Nasional. Jurnal Ilmiah WIDYA, 1, 88.

Ariesa, Y. (2019). Faktor-Faktor Yang Mempengaruhi Ketahanan Pangan Dengan Menggunakan Analisis Faktor Konfirmatori. Jurnal Abdi Ilmu, 2(1), 8-18.

Bahri, S. 2018. Metode Penelitian Bisnis. ANDI (Anggota IKAPI). Yogyakarta

BPS. 2019. Sumatera Utara DalamAngka. Provinsi Sumatera Utara.

BPS. 2019. Statistika Daerah Sumatera Utara. Provinsi Sumatera Utara.

Darus, D., Fahrial, F., \& Efendi, R. A. (2020). a Peran Kelembagaan Agribisnis Dalam Menyukseskan Program Ketahanan Pangan Riau Di Kabupaten Rokan Hulu. Jurnal Agribisnis, 21(2), 198-212. https://doi.org/10.31849/agr.v21i $\underline{2.3474}$

Desi Novita, H. G. (2017). Determination of the Main Sector in the Economy of Regency Region. 21(1), 49-54.

Effendi, Ernawati. 2012. Peningkatan Ketahanan Pangan Di Daerah Perbatasan : Studi Kasus Kabupaten Belu Provinsi Nusa Tenggara Timur. Jurnal Sosioteknologi. Edisi 27 Tahun 11, Desember 2012

Elizabeth, R. (2019). Peningkatan partisipasi petani, pemberdayaan kelembagaan dan kearifan lokal mendukung ketahanan pangan berkelanjutan. Agribisnis Dan Sosial Ekonomi Pertanian UNPAD, 4(2528), 48-61.

Hidayat, S. I., \& Rofiqoh, L. L. (2020). Analisis Alih Fungsi Lahan 
Pertanian Di Kabupaten Kediri. Jurnal Social Economic of Agriculture, $\quad 9(1), \quad 59$. https://doi.org/10.26418/j.sea.v9i 1.40646

Ifgayani, T., Antara, M., Damayanti, L., Kunci, K., Produksi Cobb-Douglas, F., Sawah, P., \& Regresi, dan. (2019). The Analysis On Factors Affecting Wetland Rice Production In Uetoli Village Ampana Tete SubDistrict Of Tojo Una-Una District. J. Agroland, 26(2), 111-122.

Jaya, Pajar Hatma Indra. 2018. Nasib Petani Dan Ketahanan Pangan Wilayah: Studi Tentang Kebijakan Pemerintah Dan Respons Masyarakat Desa Mulyodadi, Bantul Ketika Harga Komoditas Pertanian Naik. Jurnal Ketahanan Nasional. Volume 24, No. 1, April 2018 : 77 93

Juarini. (2015). Pengelolaan Sumberdaya Manusia Pertanian Untuk Menunjang Kedaulatan Pangan. Seminar Nasional Universitas PGRI Yogyakarta, 111(c), 412-418.

Lubis, Zulkarnain. dkk. 2018. Panduan Pelaksanaan Penelitian Sosial. Perdana Mulya Sarana (Anggota IKAPI). Medan.

Marsigit, Wuri. 2010. Pengembangan Diversifikasi Produk Pangan Olahan Lokal Bengkulu untuk Menun jang Ketahanan Pangan Berkelanjutan Development of Bengkulu Local Food Processing Products Diversity to Support Sustainable Food Security Wuri Marsigit. Agritech, 30(4).

Muhajirin, dkk. 2014. Analisis FaktorFaktor Yang Mempengaruhi Produksi Usahatani Padi Sawah Di
Kecamatan Batang Asai Kabupaten Sarolangun. Sosio Ekonomika Bisnis. Volume 17 No. 1

Pusvita, E., Sriati, S., \& Adriani, D. (2019). Analisis Strategi Penguatan Ketahanan Pangan Beras Di Kabupaten Ogan Komering Ulu. SEPA: Jurnal Sosial Ekonomi Pertanian Dan Agribisnis, 15(2), 97. https://doi.org/10.20961/sepa.v15 i2.27862

Pujiati,Sri. dkk. 2020. Analisis Ketersediaan, Keterjangkauan Dan Pemanfaatan Pangan Dalam MendukungTercapainya Ketahanan Pangan Masyarakat Di Provinsi Jawa Tengah. Jurnal Sosial Ekonomi Pertanian. Vol. 16, No. 2, Juni 2020.

Rahmanta, 2014. Ekonomi Pertanian. USU Press. Medan

Rangkuti, F. 2009. Analisis SWOT Teknik Membedah Kasus Bisnis. Penerbit PT. Gramedia Pustaka Utama. Jakarta.

Suryana, Achmad. 2014. Menuju Ketahanan Pangan Indonesia Berkelanjutan 2025 : Tantangan Dan Penanganannya. Forum Penelitian AgroEkonomi. Volume 32 No. 2, Desember 2014: 123 - 135.

Suliyanto. 2018. Metode Penelitian Bisnis. ANDI OFFSET (Anggota IKAPI). Yogyakarta

Supranto, J. 1989. Metode Ramalan Kuantitatif Untuk Perencanaan. Edisi Kedua. Jakarta PT.Gramedia.

Suvriana, T. 2016. Metode Penelitian Sosial Ekonomi. USU Press. Medan Widodo, et al. (2013). Perencanaan Pembangunan Distribusi dan Akses Pangan Masyarakat (Studi pada Kantor Ketahanan Pangan Kabupaten Banyuwangi). Wacana, 16(4), 223-232. 
Appendix 1.

\begin{tabular}{|c|c|c|}
\hline INTERNAL & $\begin{array}{l}\text { STRENGTHS (S) } \\
\text { - Koordinasi Kelembagaan } \\
\text { - Komitmen Pemerintah } \\
\text { daerah }\end{array}$ & $\begin{array}{l}\text { WEAKNESS (W) } \\
\text { - Peran SDM } \\
\text { - Sosialiasi Program } \\
\text { - Luas lahan }\end{array}$ \\
\hline $\begin{array}{l}\text { OPPORTUNITIES } \\
\text { (O) } \\
\text { - Infrastruktur } \\
\text { pangan } \\
\text { - Teknologi } \\
\text { pangan lokal } \\
\text { - Kondisi Letak } \\
\text { daerah }\end{array}$ & $\begin{array}{l}\text { STRATEGI SO } \\
\text { 1) Meningkatkan peran } \\
\text { antar kelembagaan, dan } \\
\text { pemanfaatan } \\
\text { infrastruktur pangan saat } \\
\text { ini yang sudah baik } \\
\left(\mathrm{S}_{1}, \mathrm{O}_{1}\right) \text { melihara } \\
\text { 2) Untuk tetap memelihan } \\
\text { komitmen pemerintah } \\
\text { daerah dalam } \\
\text { mewujudkan ketahanan } \\
\text { pangan, melalui berbagai } \\
\text { kebijakan untuk } \\
\text { teknologi pangan lokal } \\
\left(\mathrm{S}_{2}, \mathrm{O}_{2}\right)\end{array}$ & 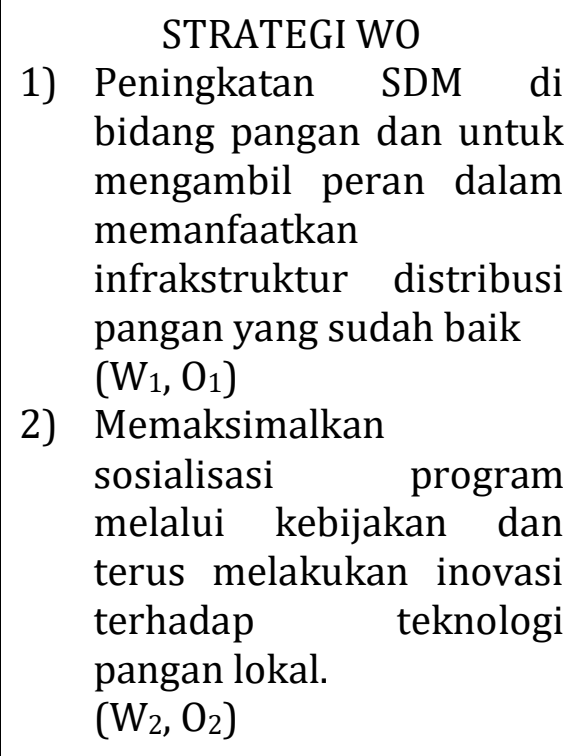 \\
\hline $\begin{array}{l}\text { THREATS }(\mathrm{T}) \\
\text { - } \quad \text { Alih fungsi } \\
\text { - } \quad \text { Harga pangan } \\
\text { - } \quad \text { Lembaga } \\
\\
\text { penelitian }\end{array}$ & $\begin{array}{l}\text { STRATEGI ST } \\
\text { 1) Melakukan integrasi } \\
\text { antar kelembagaan dan } \\
\text { penyuluhan pertanian, } \\
\text { untuk menyelesaikan } \\
\text { persoalan petani untuj } \\
\text { tidak melakukan } \\
\text { perubahan fungs ke } \\
\text { lahan komersil atau non } \\
\left.\text { usahatani.(S } \mathrm{S}_{1}, \mathrm{~T}_{1}\right) \\
\text { 2) Dengan komitmen } \\
\text { pemerintah daerah yang } \\
\text { ingin mewujudkan } \\
\text { ketahanan pangan } \\
\text { supaya tetap mengawasi } \\
\text { fluktuasi harga dan } \\
\text { berkolaborasi dengan } \\
\text { lembaga penelitian untuk } \\
\text { mengetahui berbagai } \\
\text { persoalan pertanian } \\
\left(\mathrm{S}_{2}, \mathrm{~T}_{2}, \mathrm{~T}_{3}\right)\end{array}$ & 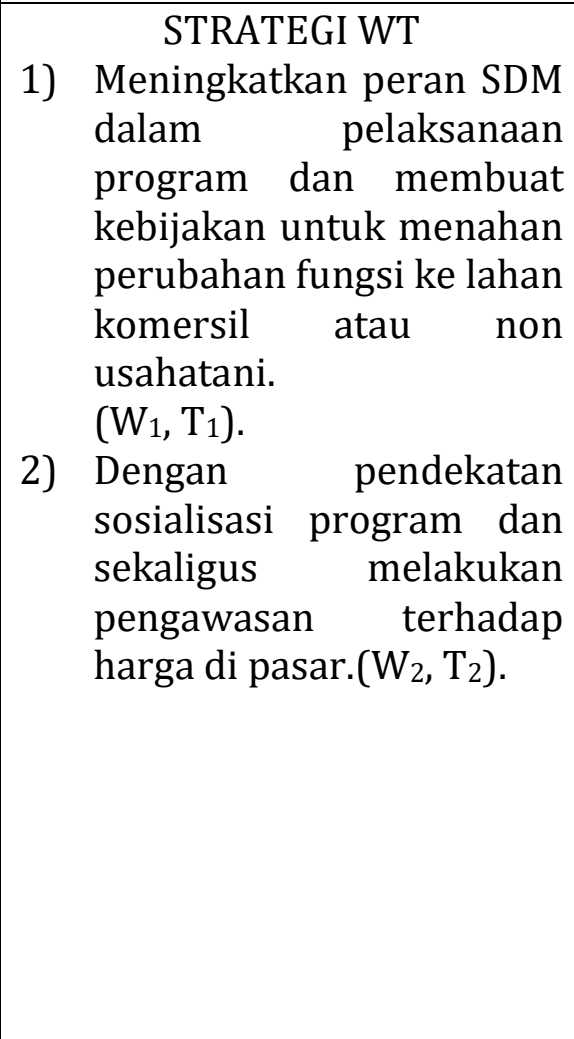 \\
\hline
\end{tabular}

